\section{La empatía: una necesidad en la educación superior}

\section{Empathy: A necessity in higher education}

\section{Sr. Director:}

Leí con interés el artículo «Evaluación de la empatía en estudiantes de Medicina», de Grau et al. ${ }^{1}$, en el que realizan un análisis para conocer el nivel de empatía de los estudiantes de Medicina de una universidad y su evolución después de recibir un curso sobre Entrevista Clínica y Comunicación. Dicha investigación motivó la elaboración de esta carta con el objetivo de seguir investigando, en el ámbito educativo, el aporte de la empatía como vía de mejora para el desarrollo socioemocional de los estudiantes y futuros profesionales $^{2}$.

Durante los últimos años, en la educación superior se ha enfatizado y estudiado la inteligencia emocional y, en específico, la empatía se ha vuelto una condición favorable en el mantenimiento de las buenas relaciones humanas.

Los diferentes estudios en profesionales de salud refieren que la empatía se relaciona con características prosociales como, por ejemplo, al momento de recabar datos de la historia clínica, o la mejora de una intervención terapéutica, lo que otorga mejores resultados clínicos y aumenta el grado de satisfacción entre el médico y el paciente ${ }^{3}$.

El análisis del estudio recogido nos muestra que los estudiantes expresan mayores niveles de empatía cognitiva y menores de empatía emocional, y estos pueden aumentar durante los estudios de Medicina ${ }^{1}$. En este sentido, el equilibrio y el dominio de la capacidad empática son factores muy importantes en la formación de los profesionales de salud, y se debe considerar que uno de ellos, y motivo de estudio, es la influencia docente o los modelos que observa el estudiante en su etapa de formación, donde se busca la adquisición de competencias cognitivo-conductuales que le permitan canalizar adecuadamente todas aquellas situaciones complejas en el acontecer profesional.

Por tanto, la condición empática es uno de los principales factores que desarrollar en la educación superior, la cual radica en formar profesionales no solo con competencias científicas, sino con competencias personales que lo posicionen como un referente capaz de poner en marcha sus actitudes, aptitudes, habilidades y sus recursos psicológicos para resolver con eficacia cualquier situación que requiera resultados eficaces; en este sentido, estas competencias debieran tenerse en cuenta para la implementación de estrategias de enseñanza-aprendizaje que promuevan los niveles de formación en competencias personales durante los primeros años de estudios ${ }^{4}$.

\section{Conflicto de intereses}

Ninguno.

\section{Bibliografía}

1. Grau A, Toran P, Zamora A, Quesada M, Carrión C, Velert $E$, et al. Evaluación de la empatía en estudiantes de Medicina. Educ Méd. 2017;18:114-20, http://dx.doi.org/10.1016/ j.edumed.2016.04.001

2. Extremera Pacheco N, Fernández-Berrocal P. El papel de la inteligencia emocional en el alumnado: evidencias empíricas. Rev Electrón Invest Educ. 2004;6:1-17.

3. Dávila Pontón Y, Neira Molina V, Aguilera Muñoz J, Martinez Reyes F, Velez Calvo X, Diaz-Narváez V, et al. La empatía y estudiantes de Medicina en la Universidad de Azuay, Ecuador. Revista Científica Salud Uninorte. 2017;33:39-47.

4. Madera-Anaya M, Tirado-Amador L, González-Martínez F. Factores relacionados con la empatía en estudiantes de Enfermería de la Universidad de Cartagena. Enferm Clín. 2016;26:282-9, http://dx.doi.org/10.1016/j.enfcli.2016.06.004

Ronald $M$. Hernández ${ }^{1}$

Universidad San Ignacio de Loyola, La Molina, Lima, Perú Correo electrónico: rhernandezv@usil.edu.pe

${ }^{1}$ Coordinador de Publicaciones Científicas. Licenciado en Psicología Educativa con estudios concluidos de Maestría en Educación.

https://doi.org/10.1016/j.edumed.2017.07.026

1575-1813/

(c) 2017 Elsevier España, S.L.U. Este es un artículo Open Access bajo la licencia CC BY-NC-ND (http: / / creativecommons.org/ licenses/by-nc-nd/4.0/). 